\section{Access to Government Information}

The ALA Washington Of ce works to support equal, ready, and equitable access to information collected, compiled, produced, funded, and/or disseminated by the government of the United States. We believe that access to government information is essential to preserving a functioning democracy. But despite our best efforts, we re losing on many fronts in the battle for open government.

\section{Save the date for the first-ever national Sunshine Sunday}

What is Sunshine Sunday? Sunshine Sunday is a day dedicated to highlighting the value of public access to government information and the dangers of ever-expanding government secrecy.

With nancial support from the Knight Foundation, the rst-ever national Sunshine Sunday is planned for March 13, 2005. We are seeking to educate the public about the importance of access to information at the federal level. Our goal is to show how access to government information affects people in their everyday lives. Sunshine Sunday will be the kickoff for a week $s$ worth of activities related to open government.

The American Society of Newspaper Editors (ASNE) is spearheading this project but is reaching out for broad support and involvement through the Coalition of Journalists for Open Government. The Sunshine Sunday steering committee includes more than 50 representatives of major journalist groups and media organizations, including the Society of Professional Journalists, Investigative Reporters and Editors, AP Managing Editors, the Newspaper Association of America, the National Newspaper Association, and the First Amendment Center. Also serving on the steering committee are top executives of the Associated Press and most major newspaper groups.

Bernadette Murphy is communications specialist at ALA's Washington Office, e-mail: bmurphy@alawash. org
A Sunshine Sunday Web site is being developed to support the project. It will include a tool kit for editors and news directors that will explain ways to participate and offer a range of downloadable materials, links, and resources. A partnership with the American Library Association opens the door to Sunshine Week programs on First Amendment/FOI topics at libraries across the country. We are also hoping to include public service ads and a component aimed at students.

\section{How can I get involved?}

We are looking for stories about average folks who have bene ted from freedom of information. For example: the persistent grandmother who fought to gain access to environmental records that showed a hazardous waste dump near the senior center, or the parents who battled to get state driving records that showed their kids school bus driver had multiple drunk driving convictions. Please send examples to wrofoi@optonline.net.

We also need volunteers to serve as state or regional coordinators for our Sunshine Sunday effort. You d be responsible for contacting editors and others in your area to urge them to participate, to keep a list of those who agree to take part, and to help us collect the content published or broadcast during the week of Sunshine Sunday. ASNE will be making the initial contact with editors about the project and publicizing its Sunshine Sunday Web site. In addition, background materials and talking points will be prepared to help state coordinators in their contacts; other assistance will be available as required.

Questions? Suggestions? Willing to help? Please contact Ray Ollwerther, national coordinator for the Sunshine Sunday project, at wrofoi@optonline.net or at (732) 845-4668.

For more information on the importance of open access to government information, see ALA s Key Principles on Government Information at: www.ala.org/ala/washoff/WOissues/governmentinfo/keyprins.htm. z 61

C\&RL News 